\title{
Influence of estrogen levels on thermal perception, pain thresholds and pain tolerance: Studies on women undergoing in vitro fertilization
}

\author{
Kent Stening, Göran Berg, Mats Hammar, Helene Voster, Olle Eriksson, \\ Åsa Amandusson and Anders Blomqvist
}

\section{Linköping University Post Print}

N.B.: When citing this work, cite the original article.

Original Publication:

Kent Stening, Göran Berg, Mats Hammar, Helene Voster, Olle Eriksson, Åsa Amandusson and Anders Blomqvist, Influence of estrogen levels on thermal perception, pain thresholds and pain tolerance: Studies on women undergoing in vitro fertilization, 2012, Journal of Pain, (13), 5, 459-466.

http://dx.doi.org/10.1016/j.jpain.2012.01.446

Copyright: Elsevier http://www.elsevier.com/

Postprint available at: Linköping University Electronic Press http://urn.kb.se/resolve?urn=urn:nbn:se:liu:diva-71869 


\section{Influence of estrogen levels on thermal perception, pain thresholds and pain}

tolerance: Studies on women undergoing in vitro fertilization

Kent D. Stening ${ }^{1,2}$, Göran Berg ${ }^{3}$, Mats Hammar ${ }^{3}$, Helene Voster ${ }^{1}$, Olle Eriksson ${ }^{4}$, Åsa Amandusson $^{5}$, Anders Blomqvist ${ }^{1}$

${ }^{1}$ Division of Cell Biology, Department of Experimental and Clinical Medicine, Faculty of Health Sciences, Linköping University, S-581 85 Linköping, Sweden; ${ }^{2}$ Department of Health and Caring Sciences, Linnaeus University, S-391 82 Kalmar, Sweden; ${ }^{3}$ Obstetrics and Gynecology, Department of Experimental and Clinical Medicine, Faculty of Health Sciences, Linköping University, S-581 85 Linköping, Sweden; ${ }^{4}$ Department of Computer and Information Science (IDA), Division of Statistics, Linköping University, S-581 83 Linköping, Sweden; ${ }^{5}$ Department of Neuroscience, Division of Clinical Neurophysiology, Uppsala University, S-751 85 Uppsala, Sweden.

Running title: Estrogen levels and pain sensitivity during IVF

25 pages; 4 tables

Correspondence to: Dr. Anders Blomqvist, Division of Cell Biology, Department of Clinical and Experimental Medicine, Faculty of Health Sciences, Linköping University, S-581 85 Linköping, Sweden. Phone: +46101033193; Fax: +46101033192; E-mail: anders.blomqvist@liu.se 


\begin{abstract}
We examined the relationship between estrogen and pain in women undergoing in vitro fertilization (IVF). Quantitative sensory tests (QST) were performed twice during the IVF-regimen: once during hormonal down-regulation and once during hormonal upregulation. A group of healthy men and a group of women using monophasic contraceptives were also examined, to control for session-to-session effects. Among the women undergoing IVF, serum 17 $\beta$-estradiol levels differed strongly between treatments as expected, and increased from $65.7(\mathrm{SD}=26) \mathrm{pmol} / \mathrm{l}$ during the downregulation phase, to $5188(\mathrm{SD}=2524) \mathrm{pmol} / \mathrm{l}$ during the up-regulation phase. Significant outcomes in the QST were only seen for temperature perception thresholds $\left(1.7^{\circ} \mathrm{C}\right.$ vs. $\left.2.2^{\circ} \mathrm{C} ; P=0.003\right)$ and cold pain threshold $\left(11.5^{\circ} \mathrm{C}\right.$ vs. $\left.14.5^{\circ} \mathrm{C} ; P=0.04\right) . \mathrm{A}$ similar change in cold pain threshold was also seen in the two control groups, however, and statistical analysis suggested that this change was due to a session-to-session effect rather than being the result of hormonal modulation. Heat pain thresholds, heat tolerance, pressure pain thresholds, and the cold pressor test showed no significant differences between sessions. These data demonstrate that pain perception and pain thresholds in healthy women show little, if any, changes even with major variations in serum estradiol levels.
\end{abstract}

\title{
Perspective
}

This study shows that pain perception and tolerance in women undergoing in vitro fertilization do not vary, despite the dramatic changes in $17 \beta$-estradiol levels induced by the treatment regimen. The result thus suggests that in humans, contrary to experimental animals, changes in estrogen levels have little influence on pain sensitivity.

Key words: 17ß-estradiol; in vitro fertilization; quantitative sensory testing; pain thresholds; pain tolerance 


\section{Introduction}

In addition to their major influence on development and reproductive functions, gonadal steroid hormones have been reported to have significant effects on pain perception and modulation in animals as well as humans. ${ }^{9}$ Some effects are well established, such as the opioid-dependent increase in pain threshold during pregnancy, ${ }^{8,33}$ whereas others, such as those reported to occur with the hormonal changes seen during normal menstrual cycling, are less uniform and seem to vary considerably with the experimental set-up. ${ }^{7,12,27,45}$ Hence, lowered ${ }^{19,20}$ as well as increased ${ }^{5,41}$ pain thresholds have been observed during phases with low gonadal hormone levels. A general weakness of many studies on changed pain sensitivity across the menstrual cycle has been the lack of reliable methods to determine cycle phase, as pointed out by Sherman and LeResche. ${ }^{36}$ However, even studies verifying cyclicity by repeated hormonal measurements remain contradictory, ${ }^{13,24,25,34,39}$ suggesting that the differences in outcome may either be related to a much too blunt test protocol examining a limited amount of modalities or that the possible changes induced by the normal fluctuations in hormone levels are too small to measure reliably. In an attempt to overcome these limitations in the present study, we have used a comprehensive quantitative sensory testing (QST) protocol to examine pain thresholds and pain tolerance during the highly dichotomous levels of estradiol seen in women undergoing in vitro fertilization (IVF).

When IVF is initiated, gonadotropin-releasing hormone $(\mathrm{GnRH})$-analogues are used to prevent spontaneous ovulation. This treatment induces, by impairing pituitary stimulation of the ovaries, a hormonal state quite similar to that during menopause, with very low serum estradiol levels, ${ }^{17}$ whereas the secretion of other pituitary hormones such as thyroid-stimulating hormone (TSH) and adrenocorticotropic hormone (ACTH) is only affected to a minor extent. Once this state of down regulation of gonadal hormones has been reached, treatment with follicle-stimulating hormone (FSH)analogues is initiated in order to stimulate follicle development and maturation, and steroidogenesis, in turn leading to a rapid increase in estradiol release while progesterone and luteinizing hormone (LH) levels are kept low. This set-up thus offers the possibility to study pain perception in relation to extreme changes in estradiol levels in the same individual. 
While responses to some pain stimuli have been examined during IVF treatment previously, ${ }^{31,43}$ we here provide data from a comprehensive sensory testing protocol that examines different thin fiber modalities. We have employed a within-subject design to evaluate thresholds and tolerance to acute thermal pain, to pressure pain, and to tonic cold pain, at very low and very high serum levels of estradiol. Control groups with stable gonadal hormone levels were included to check for changes in the measured variables that may occur as a result of repeated measurements in the same individual.

\section{Materials and methods}

\section{Subjects}

Women undergoing IVF $(n=16)$, were recruited from the gynecological clinic at Linköping University Hospital, Sweden. Their mean age was 33 years, spanning from 25 years to 41 years. Since this group of women had been thoroughly investigated prior to being accepted for IVF, the inclusion criteria to participate in the present study followed the criteria for suitability for IVF, i.a., a stable relation for the past two years, FSH levels below $11 \mathrm{IU} / \mathrm{l}$ and Body Mass Index $<30 \mathrm{~kg} / \mathrm{m}^{2}$. The indication for IVF treatment was ovarian dysfunction $(n=3)$, male infertility $(n=1)$, "unknown" $(n=5)$, and combined female and male factors causing infertility $(n=7)$. In addition, patients with diabetes or other diseases that may influence the peripheral sensory nervous system were excluded. One of the included women suffered from a non-painful variant of Thomsen's disease (congenital myotonia) and one suffered from ulcerous colitis. No intake of analgesics was allowed within 24 hours before testing.

The primary topic of the present study was to evaluate the hormonal influence on pain in a within-subject design. The sample size was calculated for a significance level of 0.05 with $85 \%$ power based on differences previously found in response to hormone replacement therapy in a pilot study where the same testing paradigm was used (Stening et al, 1999, data not published). However, since we and others have shown that quantitative sensory methodology is sensitive to session-to session effects ${ }^{39}$ (see below), two control groups were recruited using the same inclusion and exclusion criteria as above (when relevant) to control for such session-to-session effects. The first consisted of 10 healthy men aged 21 to 38 (mean age 25), recruited among students and staff at Linköping University. The second consisted of 9 healthy women aged 20 to 24 
(mean age 21) using monophasic oral contraceptives, which give rise to continuously low levels of endogenous estradiol as well as progesterone. They were recruited among students at the Linnaeus University, Kalmar. While this group is younger than that undergoing IVF (it was not feasible to obtain an age-matched control group on monophasic oral contraceptives), there is no evidence that QST-recordings differ significantly with age within the age-span of 20-40 years. ${ }^{28}$

\section{Equipment and test set-up}

In each session, QST was first used to measure thermal perception thresholds (to assure that the participants had normal temperature sensitivity), and then heat and cold pain thresholds, heat pain tolerance, and pressure pain threshold, followed by a cold pressor test to measure the tolerance time to tonic pain. These variables were considered to be of primary importance. In addition, but considered to be of secondary importance, VAS ratings were performed to estimate perceived pain during the heat pain tolerance test, and during and after the cold pressor test. The different methods of testing are described separately in detail below. Each session took approximately 50 min in total to perform.

Temperature and pain thresholds were measured using a 2.5 x $5 \mathrm{~cm}$ peltier element-based thermode (Thermotest; Somedic, Hörby, Sweden) connected to a standard IBM computer. The thermode was applied to the thenar region of the right hand. The thenar region was chosen because QSTs on this site have shown small interindividual variation. ${ }^{15}$ Thenar region measurements have been shown to accurately reflect overall pain sensitivity with high method sensitivity and reproducibility. ${ }^{37,38}$

To measure the thermal perception threshold, done according to the method of limits, ${ }^{37}$ four cold stimuli followed by four warm stimuli (starting at $32 \pm 0.5^{\circ} \mathrm{C}$; and with stimulus rate of $1^{\circ} \mathrm{C} / \mathrm{s}$ ) were given with a randomized inter-stimulus interval of 4-6 $\mathrm{s}$, the latter with the purpose of avoiding habituation by the test subjects. The subject was instructed to press a cut-off button as soon as she/he perceived the sensation of heat or cold, respectively. The average of the difference between the heat and cold perception thresholds was then calculated, and considered to represent the thermal perception threshold. 
To determine cold pain threshold, five cold stimuli, starting from $32 \pm 0.5^{\circ} \mathrm{C}$ with a cut-off temperature of $+2^{\circ} \mathrm{C}$, were given at a randomized inter-stimulus interval of 4-6 s (stimulus rate $1{ }^{\circ} \mathrm{C} / \mathrm{s}$ ). The subject was instructed to press the cut-off button immediately when the cold sensation was perceived as painful. The first recording was excluded and the average value was calculated from the four following recordings. Heat pain threshold was measured using the same strategy. Ten heat stimuli, starting at $32 \pm$ $0.5^{\circ} \mathrm{C}$ with a cut-off temperature of $+52^{\circ} \mathrm{C}$ were given at a randomized inter-stimulus interval of 4-6 s (stimulus rate $1^{\circ} \mathrm{C} / \mathrm{s}$ ). The subject was instructed to press the cut-off button when the heat sensation was perceived as painful. The average value of the recordings was calculated.

A supra-threshold test for heat pain tolerance was then performed. Four stimuli were given, starting at $32 \pm 0.5^{\circ} \mathrm{C}$ (stimulus rate $3^{\circ} \mathrm{C} / \mathrm{s}$ ) with a cut-off temperature of $+52^{\circ} \mathrm{C}$ and with an inter-stimulus interval of 4-6 s. The subject was instructed to press the button when the pain sensation was intolerable; the average value of the four stimuli was used as a measure of heat pain tolerance. Immediately after the four heat stimuli the subject was asked to rate her/his perceived intensity of induced pain on a $100 \mathrm{~mm}$ visual analogue scale (VAS)-instrument anchored by "no pain" on the left and "worst possible pain" on the right.

Following the thermal tests described above, pressure pain thresholds were determined using a pressure algometer (Somedic). A $1 \mathrm{~cm}$ probe was applied perpendicular to the skin and pressed with an increasing force rate of $50 \mathrm{kPa} / \mathrm{s}$ until the subject verbally reported pressure to be painful. The pressure pain threshold was defined bilaterally at four of the 18 tender points used in the diagnosis of fibromyalgia: (i) the midpoint of the upper border of the trapezius muscle; (ii) $2 \mathrm{~cm}$ distal to the lateral epicondyle of the elbow; (iii) the upper outer quadrant of the gluteal region; and (iv) the medial fat pad proximal to the knee joint line. ${ }^{46}$ These four points cover both axial and distal parts of the body as well as each body quadrant when measured bilaterally. Three stimuli were applied on each site with an inter-stimulus interval of $2 \mathrm{~min}$. The mean value of three stimuli was considered the pressure pain threshold. During measurements, no significant side differences were seen and data from the left and right side were therefore pooled before further statistical analysis of pressure pain thresholds. 
To study the response to tonic pain, a modified cold pressor test was used. This test was chosen above other tonic pain tests such as compression-induced ischemia due to the higher degree of subject control and better test-retest reliability. ${ }^{11}$ The subject's left hand was immersed down to the wrist in a water tub (2.8 1) filled with ice-chilled water $\left(1.5 \pm 0.5^{\circ} \mathrm{C}\right)$. The temperature in the tub was monitored with a steel probe digital thermometer (VEE GEE Scientific, Kirkland, WA, USA) and never reached above $2^{\circ} \mathrm{C}$. To avoid warming of the water next to the skin, an air-driven pump was used to induce circulation in the water tub. The subject was instructed to hold her/his left hand in the ice water as long as possible, or until the cut-off limit of $300 \mathrm{~s}$ was reached. Throughout the cold pressor test, the subject continuously graded the perceived pain sensation using a computerized VAS-rating system (Pain-Test; Archebyte, Kalmar, Sweden) with a screen showing a line marked "no pain" on the left and "worst possible pain" on the right. The following outcomes were measured: 1 ) activation time (the time point at which the subject reached a VAS rating level of 30 out of 100 , considered to represent the transition between mild and moderate pain ${ }^{16}$ ); 2) tolerance time (the time period the subject managed to keep her hand immersed in the water); and 3) maximum VAS rating level (the maximum VAS rating level that occurred during the two sessions at a given time point). These recordings were followed by a post-stimulus rating, performed $30 \mathrm{~s}$ after the participants had withdrawn their hand, using the manual 100-mm VAS instrument described above. The participants were asked to rate their actual pain sensation at that time.

\section{Hormonal treatment during IVF}

The subjects followed the standard regimen for IVF at Linköping University Hospital. This regimen is highly individualized when it comes to the drug of choice as well as the dose given, and subsequent dose adjustments are made based on the response to treatment in each patient. Therefore, drug generics and doses typically vary. Nevertheless, the principle of treatment was the same in all patients. The hormonal treatment started with a period of down-regulation of the hypothalamic-pituitarygonadal (HPG) axis induced by GnRH-analogues [Suprecur ${ }^{\circledR}$ (Sanofi-Aventis, Paris, France), or Synarela ${ }^{\circledR}$ (Pfizer Inc., New York, NY, USA); doses adjusted according to weight, age and FSH-levels)]. In the present study, the average length of treatment was 
$16(\mathrm{SD}=2.3)$ days, with a range of 14 to 21 days. When a state of down-regulation was reached, as confirmed by venous blood-samples of $17 \beta$-estradiol and ultrasound examination of the thickness of the endometrium, the up-regulation phase was induced using follicle-stimulating hormonal treatment [(4 patients received Gonal- $\mathrm{f}^{\circledR}$ (Merck Serono S.A., Geneva, Switzerland); 9 patients received Puregon ${ }^{\circledR}$ (Schering-Plough $\mathrm{AB}$, Stockholm, Sweden); and 3 patients received Menopur ${ }^{\circledR}$ (Ferring SA Holding, Lausanne, Switzerland)]. Average length of treatment was $12(\mathrm{SD}=2.8)$ days with a range of 8 to19 days. Ovarian maturation was monitored and doses were subsequently adjusted (in general 75-225 IE/day for Gonal- $\mathrm{f}^{\circledR} ; 150-450 \mathrm{IE} /$ day for Puregon ${ }^{\circledR}$; and 75$225 \mathrm{IE} /$ day for Menopur ${ }^{\circledR}$ ). When the follicles reached a size of $18 \mathrm{~mm}$ a human chorionic gonadotropin (hCG) injection was given (Pregnyl ${ }^{\circledR}, 10000 \mathrm{IE}$; MSD, Sollentuna, Sweden). Oocyte retrieval was then performed at 36-38 hours after the hCG injection. Eleven out of the 16 participating women received their hCG injection after the second QST session, and the remaining four women received their injection immediately prior to the second QST-testing. Hormonal treatment was interrupted in one subject because of absence of ovulatory response, and in this case the test procedure was carried out after 9 days of FSH treatment.

\section{Test procedure}

QST-sessions, as described above, were carried out twice in all study groups. Among the women undergoing IVF, the first session was performed at the termination of the down-regulation phase. On the same day, following QST, all women were instructed to start follicle-stimulating treatment. The women were then followed by ultrasound to see follicle development, and by blood samples measuring $17 \beta$-estradiol levels to verify the effect of the FSH stimulation. Serum concentrations of 17ß-estradiol were determined by immunoassay (Cobas e 602; Roche, Basel, Switzerland). In the control group with women using monophasic contraceptives, serum progesterone was analyzed using immunoassay (Immulite 2500; Siemens, Eschborn, Germany). The second QSTsession was carried out prior to oocyte retrieval, in average 12 days (varying between 8 and 19 days) after the first session. The control group of men was tested with an interval of 15 days between sessions (range 14 to 23 days), while the group of women using contraceptives underwent testing with an interval of 12 days between sessions (8-16 
days). All tests on the two groups of women (IVF and control) were carried out by the same investigator, using the same equipment, but at two different locations. The tests on the control group of men were carried out by a second investigator, but with the same equipment as for the two other groups, and at the same location as for the IVF group.

The study was approved by the regional ethics committee in Linköping, Sweden, and adheres to the principles of the Declaration of Helsinki. All subjects gave their written as well as oral consent to participate. They were informed that they could discontinue the study whenever they wanted and without giving any reason for their decision.

\section{Statistical analyses}

All statistical analyses were performed using MiniTab, version 16 (Minitab Inc., State Collage, PA, USA) and SPSS, version 17 (IBM, Chicago, IL, USA). An Analysis of Variance (ANOVA) was used in which "Group" and "Session" were fixed factors and "Person" was a random factor nested within group. Further, an interaction between "Group" and "Session" was also included in the model. For the subsequent comparisons, Student's paired $t$-test was used to compare sessions within group; Student's independent samples $t$-test was used to compare pairs of groups within sessions and changes across sessions between pairs of groups; and linear regression was used to compare changes across sessions between the treatment group and the mean of the two control groups. Correlation analysis was also performed using Pearson correlation between hormonal level and the outcomes from the QSTs.

All data are presented as mean and standard deviation. Statistical significance was set to $P<0.05$.

\section{Results}

As expected, serum levels of $17 \beta$-estradiol differed greatly between test sessions. Thus, the down-regulation of the HPG-axis by GnRH-analogues resulted in serum $17 \beta$ estradiol levels of in average $66(\mathrm{SD}=26) \mathrm{pmol} / \mathrm{l}$, ranging between 44-140 pmol/l. Subsequent treatment with FSH analogues resulted in estradiol levels of 5188 (SD = 2524) pmol/l, ranging between 2040 and $10200 \mathrm{pmol} / \mathrm{l}$. No significant differences in $17 \beta$-estradiol levels were seen between the three different FSH-analogues used. The 
estradiol levels during the up-regulation phase thus clearly exceeded the upper limit of the physiological ovulatory peak of $1626 \mathrm{pmol} / 1 .{ }^{26}$ The hormonal levels in the control group of women using monophasic oral contraceptives were constantly low at both occasions as expected. Serum $17 \beta$-estradiol levels were on average $47.6(\mathrm{SD}=6.7)$ $\mathrm{pmol} / \mathrm{l}$ with a range of 44-64 pmol/l at the first session and $47.3(\mathrm{SD}=8) \mathrm{pmol} / \mathrm{l}$ with a range of 44-60 pmol/l at the second session. The corresponding values for serum progesterone was $1.1(\mathrm{SD}=0.3) \mathrm{nmol} / \mathrm{l}$ and $<1 \mathrm{nmol} / \mathrm{l}$, respectively.

Data for the QST measurements are given in Tables 1-3. As seen in Table 1, for many variables there was no Group effect or Session effect, indicating no difference between the examined groups or between sessions, respectively. This was the case for all pressure pain measurements as well as for heat pain threshold and the maximal VAS recording following the cold pressor test. Significant Session effects were seen for two variables only, namely thermal perception threshold $(P<0.03)$, and cold pain threshold $(P<0.004)$. The thermal perception threshold also showed a significant Group $\mathrm{x}$ Session effect, indicating that the Session effect was not present in all groups. Subsequent pair-wise comparison on the IVF sample (Table 2), showed significantly reduced thermal discrimination during the up-regulation phase $(P=0.003)$, an effect that was not seen in the two control groups (Table 3). A comparison of the change in thermal perception threshold between sessions that occurred in the IVF-group, with the session-to-session change that was seen in the two control groups, showed a statistically significant difference vs. the control group of men $(P=0.006)$, and vs. a weighted mean of the change in the two control groups $(P=0.02)$, but not vs. the control group of women $(P=0.23)$. These data hence indicate a hormonal effect on thermal perception threshold.

While cold pain threshold showed a strong session effect, there was no Group effect or Group x Session effect (Table 1). Accordingly, while cold pain threshold changed significantly in the IVF-group $(P=0.04)$, from $11.5^{\circ} \mathrm{C}$ at the first session to $14.5^{\circ} \mathrm{C}$ at the second session (Table 2 ), similar, although statistically not significant, changes between sessions were also seen in both control groups (Table 3). When the change between the two sessions observed in the IVF-group was compared with the change that occurred in the control groups, no statistically significant differences were found ( $P=0.47$ vs. the control group of men; $P=0.85$ vs. the control group of women; 
and $P=0.75$ vs. both control groups). These data indicate that the effect seen was due to the repeated measurement design.

For some of the variables, such as heat pain tolerance and activation and tolerance time in the cold pressor test, as well as the pain rating subsequent to the cold pressor test, there were significant group effects. Subsequent analysis showed that most of these group effects could be ascribed to sex differences (see Table 3). Thus, at both sessions the control group of women displayed significantly lower heat pain tolerance than the control group of men, $P=0.004$ and $P=0.006$, respectively), as well as shorter tolerance time $(P=0.06$ and $P=0.05)$ and higher after sensation VAS rating $(P$ $=0.003$ and $P=0.001)$ in the cold pressor test.

Finally, the data were analyzed with respect to the relationship between serum estradiol levels and the measured QST outcome in the IVF treated group. During the down regulation phase serum estradiol levels were low throughout, displaying little ingroup variation (see above), and no significant correlations were hence seen (data not shown). While the up regulation phase displayed a much larger variation in serum estradiol levels (see above), for all QST outcomes but cold pain threshold, no statistically significant correlation to serum estradiol levels was seen (Table 4). For cold pain threshold, however, there was a moderate negative correlation between this variable and serum estradiol level $(r=-0.55, P=0.02)$.

\section{Discussion}

In the present study a comprehensive set of quantitative sensory tests was performed in women undergoing IVF, an experimental set-up offering the possibility to study different aspects of pain perception and tolerance at highly different $17 \beta$-estradiol levels. In contrast to the abundant reports from animal studies of gonadal steroid hormone influence on pain, ${ }^{9,29}$ no measurable effects were seen despite the major variations in serum $17 \beta$-estradiol induced by the IVF-treatment. The only unambiguous exception, which was not related to pain, was the thermal perception threshold, which was reduced in the up-regulation phase during which $17 \beta$-estradiol levels were high. It remains to be clarified whether the reduced thermal discrimination results from hormonal modulation of the processing of thermal stimuli in the central somatosensory 
pathways or if it is related to peripheral factors such as minimal changes in skin thickness or increased vascular blood flow.

While cold pain threshold also showed a difference between the test sessions, this difference may not have been due to changes in hormone levels, but a result of the test situation. Although the semi-objective methods used in the QST measurements have high method sensitivity and reproducibility in healthy adults, ${ }^{30,38}$ session-tosession effects must always be taken into account when interpreting the data. These session-to-session effects are a well-known confounder in semi-objective psychophysical methods such as QST and are due to the fact that subjects get used to the test situation and therefore tend to be more alert at the following session, in turn resulting in modified thresholds and tolerance time over time. ${ }^{30}$ In the present study, two different control groups were included to control for session-to-session effects. In these control groups, a slight, although statistically non-significant, difference was seen in the cold pain threshold with lower thresholds at the second test session. Statistical analysis showed that the change observed for the cold pain threshold in the IVF-group did not differ significantly from the changes that occurred between sessions in the control groups, suggesting that it was a session-to-session effect. Notably cold pain threshold measures are also known to have a higher degree of variability than other QST parameters. ${ }^{30}$ However, because a moderate negative correlation was seen between the cold pain threshold, but no other variable, and serum estradiol levels during the up regulation phase (i.e. in the opposite direction to that seen between sessions), it remains possible that the cold pain threshold is influenced by estradiol, although within a much smaller range of serum estradiol level changes than that elicited by IVF-treatment.

The use of IVF patients as test subjects provides a unique possibility to study changes associated with estradiol levels ranging from the very low, menopause-like state to supra-physiological levels in the same individual within a short period of time. However, one possible limitation associated with studies that involve subjects undergoing IVF is that anxiety and stress may contribute to changes in pain perception. ${ }^{21,35}$ Not surprisingly, infertility is associated with increased levels of stress, anxiety and depression, ${ }^{10,23}$ suggesting that any effects attributed to estradiol changes in fact may be related to reduced coping/cooperation or increased sensitivity due to the different biological effects of long-term stress. Still, Verhaak et al., ${ }^{44}$ reviewing 25 years 
of research on emotional reactions in women undergoing IVF treatment, found that subjects in the treatment phase, i.e. at the time when the QST sessions were carried out in this study, displayed a lesser amount of anxiety and depression than expected. Nevertheless, anxiety and stress related to infertility may have influenced the present findings, since thresholds in the IVF group were generally lower than in the control group of women (cf. Tables 2 and 3), a difference that cannot be explained by the difference in mean age between the two groups. ${ }^{28}$ However, the clinical significance of this difference remains unclear.

To our knowledge, only two previous studies, Tsen et al., ${ }^{43}$ and Nisenblat et al., ${ }^{31}$ have used IVF patients to evaluate the hormonal influence on the sensation of pain. Both these studies had a larger sample size but neither of them included a control group, thereby leaving the possibility that their results may have been due to session-tosession effects or other factors such as anxiety and stress at the time of oocyte retrieval. Tsen et al. ${ }^{43}$ employed two pain tests: pressure algometry and ice water immersion (comparable to the activation time measure in our study). Similar to our results, no differences were noted in the response to pressure algometry, but a significant difference was noted for the ice water immersion test, with a reduction in the tolerance to cold pain when estrogen levels were high. A similar reduction in cold pain threshold was found in the present study, however, as discussed above, it may have been due to a session-to-session effect, and the same concern may be raised also vis-à-vis the finding in the study by Tsen et al. ${ }^{43}$

Nisenblat et al. ${ }^{31}$ used a thermode to study heat pain threshold and perceived pain intensity in response to phasic (stimulus duration $1 \mathrm{~s}$ ) and tonic (stimulus duration $60 \mathrm{~s})$ supra-threshold heat pain. No significant changes across sessions were seen for any of these measures, but a positive correlation between estradiol levels and pain scores were seen during the up-regulation phase. Neither of the mentioned studies measured thermal discrimination, the only measure that clearly differed in the present study.

The concept that $17 \beta$-estradiol affects pain processing is appealing and there are strong morphological and neurophysiological evidence in support for this hypothesis. ${ }^{1-}$ 4,6,9,29 Nevertheless, the underlying networks are complex and the results of studies on hormonal pain modulation in humans, particularly those using laboratory induced pain, 
remain notoriously diverse..$^{5,19,20,24,25,34,39,41}$ The clinical studies performed are generally based on a hormonal replacement therapy regimen. Some have reported an alleviating effect on muscular pain, ${ }^{14,18}$ but when the effect of estrogen vs. a combination of estrogen and progesterone was examined, only the latter reduced pain symptoms. ${ }^{14}$ However, fibromyalgia-like symptoms have been reported to be elicited both by rapid withdrawal of hormonal replacement therapy, ${ }^{22,32}$ and by treatment with GnRHanalogues that reduce estrogen levels. ${ }^{42}$ In contrast, however, in a recent double-blind study we found that hormonal-replacement therapy did not affect subjective pain (or experimental pain responses) in women suffering from chronic muscular pain, and no changes in pain were reported by the patients after the cessation of treatment either. ${ }^{40}$ In the present study, we have examined all major thin fiber sensory modalities at the very extremes of estradiol levels, thereby optimizing the possibility to discern significant effects of estradiol. Even so, no measurable changes in pain perception that could be attributed to the changing concentrations of estradiol were seen. Thus, in contrast to the large amount of data from animal studies suggesting that estrogens influence pain perception, available studies in humans on laboratory as well as clinical pain are at best contradictory and provide little support for any significant role for estrogens in human pain processing.

\section{Disclosures}

This work was supported by the Swedish Research Council (\#7879), Konung Gustav V:s 80-årsfond, the Health Research Council in the South-East of Sweden, and the Linneus University, Kalmar, Sweden. Mats Hammar receives remuneration for being on a scientific advisory board at Novo Nordisk, Denmark. All other authors have declared no conflicts of interest.

\section{References}

1. Amandusson A, Blomqvist A: Estrogen receptor-alpha expression in nociceptiveresponsive neurons in the medullary dorsal horn of the female rat. Eur J Pain 14:245248,2010

2. Amandusson A, Hallbeck M, Hallbeck AL, Hermanson O, Blomqvist A: Estrogeninduced alterations of spinal cord enkephalin gene expression. Pain 83:243-248, 1999 
3. Amandusson A, Hermanson O, Blomqvist A: Estrogen receptor-like immunoreactivity in the medullary and spinal dorsal horn of the female rat. Neurosci Lett 196:25-28, 1995

4. Amandusson A, Hermanson O, Blomqvist A: Colocalization of oestrogen receptor immunoreactivity and preproenkephalin mRNA expression to neurons in the superficial laminae of the spinal and medullary dorsal horn of rats. Eur J Neurosci 8:2440-2445, 1996

5. Bajaj P, Arendt-Nielsen L, Madsen H: Sensory changes during the ovulatory phase of the menstrual cycle in healthy women. Eur J Pain 5:135-144, 2001

6. Blomqvist A: Sex hormones and pain: A new role for brain aromatase? J Comp Neurol 423:549-551, 2000

7. Cason AM, Samuelsen CL, Berkley KJ: Estrous changes in vaginal nociception in a rat model of endometriosis. Horm Behav 44:123-131, 2003

8. Cogan R, Spinnato JA: Pain and discomfort thresholds in late pregnancy. Pain 27:6368,1986

9. Craft RM: Modulation of pain by estrogens. Pain 132 Suppl 1:S3-12, 2007

10. Csemiczky G, Landgren BM, Collins A: The influence of stress and state anxiety on the outcome of IVF-treatment: psychological and endocrinological assessment of Swedish women entering IVF-treatment. Acta Obstet Gynecol Scand 79:113-118, 2000 11. Edens JL, Gil KM: Experimental induction of pain: Utility in the study of clinical pain. Behavior Therapy 26:197-216, 1995

12. Frye CA, Bock BC, Kanarek RB: Hormonal milieu affects tailflick latency in female rats and may be attenuated by access to sucrose. Physiol Behav 52:699-706, 1992

13. Granot M, Yarnitsky D, Itskovitz-Eldor J, Granovsky Y, Peer E, Zimmer EZ: Pain perception in women with dysmenorrhea. Obstet Gynecol 98:407-411, 2001

14. Greendale GA, Reboussin BA, Hogan P, Barnabei VM, Shumaker S, Johnson S, Barrett-Connor E: Symptom relief and side effects of postmenopausal hormones: results 
from the Postmenopausal Estrogen/Progestin Interventions Trial. Obstet Gynecol 92:982-988, 1998

15. Hagander LG, Midani HA, Kuskowski MA, Parry GJG: Quantitative sensory testing: effect of site and skin temperature on thermal thresholds. Clinical Neurophysiology 111:17-22, 2000

16. Hanley MA, Masedo A, Jensen MP, Cardenas D, Turner JA: Pain interference in persons with spinal cord injury: classification of mild, moderate, and severe pain. J Pain 7:129-133, 2006

17. Hayden C: GnRH analogues: applications in assisted reproductive techniques. Eur J Endocrinol 159 Suppl 1:S17-25, 2008

18. Hays J, Ockene JK, Brunner RL, Kotchen JM, Manson JE, Patterson RE, Aragaki AK, Shumaker SA, Brzyski RG, LaCroix AZ, Granek IA, Valanis BG: Effects of estrogen plus progestin on health-related quality of life. N Engl J Med 348:1839-1854, 2003

19. Hellstrom B, Lundberg U: Pain perception to the cold pressor test during the menstrual cycle in relation to estrogen levels and a comparison with men. Integr Physiol Behav Sci 35:132-141, 2000

20. Isselee H, De Laat A, Bogaerts K, Lysens R: Long-term fluctuations of pressure pain thresholds in healthy men, normally menstruating women and oral contraceptive users. Eur J Pain 5:27-37, 2001

21. Jones A, Spindler H, Jorgensen MM, Zachariae R: The effect of situation-evoked anxiety and gender on pain report using the cold pressor test. Scand J Psychol 43:307313,2002

22. Kahn MF: Does hormone replacement therapy discontinuation cause musculoskeletal pain? Joint Bone Spine 73:488-489, 2006

23. Kee BS, Jung BJ, Lee SH: A study on psychological strain in IVF patients. J Assist Reprod Genet 17:445-448, 2000

24. Klatzkin RR, Mechlin B, Girdler SS: Menstrual cycle phase does not influence gender differences in experimental pain sensitivity. Eur J Pain 14:77-82, 2010 
25. Kowalczyk WJ, Evans SM, Bisaga AM, Sullivan MA, Comer SD: Sex differences and hormonal influences on response to cold pressor pain in humans. J Pain 7:151-160, 2006

26. Kratz A, Lewandrowski KB: Normal Reference Laboratory Values. New Engl J Med 339:1063-1072, 1998

27. Leer MN, Bradbury A, Maloney JC, Stewart CN: Elevated shock threshold in sexually receptive female rats. Physiol Behav 42:617-620, 1988

28. Magerl W, Krumova EK, Baron R, Tölle T, Treede R-D, Maier C: Reference data for quantitative sensory testing (QST): Refined stratification for age and a novel method for statistical comparison of group data. Pain 151:598-605, 2010

29. Martin VT: Ovarian hormones and pain response: a review of clinical and basic science studies. Gend Med 6 Suppl 2:168-192, 2009

30. Moloney N, Hall T, Doody C: An investigation of somatosensory profiles in work related upper limb disorders: a case-control observational study protocol. BMC Musculoskel Dis 11:22, 2010

31. Nisenblat V, Engel-Yeger B, Ohel G, Aronson D, Granot M: The association between supra-physiological levels of estradiol and response patterns to experimental pain. Eur J Pain 14:840-846, 2010

32. Ockene JK, Barad DH, Cochrane BB, Larson JC, Gass M, Wassertheil-Smoller S, Manson JE, Barnabei VM, Lane DS, Brzyski RG, Rosal MC, Wylie-Rosett J, Hays J: Symptom experience after discontinuing use of estrogen plus progestin. JAMA 294:183-193, 2005

33. Ohel I, Walfisch A, Shitenberg D, Sheiner E, Hallak M: A rise in pain threshold during labor: a prospective clinical trial. Pain 132 Suppl 1:S104-108, 2007

34. Ring C, Veldhuijzen van Zanten JJ, Kavussanu M: Effects of sex, phase of the menstrual cycle and gonadal hormones on pain in healthy humans. Biol Psychol 81:189191,2009 
35. Robinson ME, Bialosky JE, Bishop MD, Price DD, George SZ: Supra-threshold scaling, temporal summation, and after-sensation: relationships to each other and anxiety/fear. J Pain Res 3:25-32, 2010

36. Sherman JJ, Leresche L: Does experimental pain response vary across the menstrual cycle? A methodological review. Am J Physiol Regul Integr Comp Physiol 291:R245256,2006

37. Shy ME, Frohman EM, So YT, Arezzo JC, Cornblath DR, Giuliani MJ, Kincaid JC, Ochoa JL, Parry GJ, Weimer LH: Quantitative sensory testing: report of the Therapeutics and Technology Assessment Subcommittee of the American Academy of Neurology. Neurology 60:898-904, 2003

38. Siao P, Cros DP: Quantitative sensory testing. Phys Med Rehabil Clin N Am $14: 261-286,2003$

39. Stening K, Eriksson O, Wahren L, Berg G, Hammar M, Blomqvist A: Pain sensations to the cold pressor test in normally menstruating women: comparison with men and relation to menstrual phase and serum sex steroid levels. Am J Physiol Regul Integr Comp Physiol 293:R1711-1716, 2007

40. Stening KD, Eriksson O, Henriksson KG, Brynhildsen J, Lindh-Astrand L, Berg G, Hammar M, Amandusson A, Blomqvist A: Hormonal replacement therapy does not affect self-estimated pain or experimental pain responses in post-menopausal women suffering from fibromyalgia: a double-blind, randomized, placebo-controlled trial. Rheumatology (Oxford) 50:544-551, 2011

41. Tassorelli C, Sandrini G, Cecchini AP, Nappi RE, Sances G, Martignoni E: Changes in nociceptive flexion reflex threshold across the menstrual cycle in healthy women. Psychosom Med 64:621-626, 2002

42. Toussirot E, Wendling D: Fibromyalgia developed after administration of gonadotrophin-releasing hormone analogue. Clin Rheumatol 20:150-152, 2001

43. Tsen LC, Natale M, Datta S, Eappen S: Can estrogen influence the response to noxious stimuli? J Clin Anesth 13:118-121, 2001 
44. Verhaak CM, Smeenk JM, Evers AW, Kremer JA, Kraaimaat FW, Braat DD: Women's emotional adjustment to IVF: a systematic review of 25 years of research. Hum Reprod Update 13:27-36, 2007

45. Vincler M, Maixner W, Vierck CJ, Light AR: Estrous cycle modulation of nociceptive behaviors elicited by electrical stimulation and formalin. Pharmacol Biochem Behav 69:315-324, 2001

46. Wolfe F, Smythe HA, Yunus MB, Bennett RM, Bombardier C, Goldenberg DL, Tugwell P, Campbell SM, Abeles M, Clark P, Fam AG, Farber SJ, Fiechtner JJ, Franklin CM, Gatter RA, Hamaty D, Lessard J, Lichtbroun AS, Masi AT, Mccain GA, Reynolds WJ, Romano TJ, Russell IJ, Sheon RP: The American College of Rheumatology 1990 Criteria for the Classification of Fibromyalgia. Report of the Multicenter Criteria Committee. Arthritis Rheum 33:160-172, 1990 
Table 1. Results of ANOVA for the effect of used factors "group" and "session" on measured outcomes. Significant interaction indicates changes not explained by an independent factor.

\section{Outcome}

Factor

$F_{(d f)}$

$P$

\begin{tabular}{|c|c|c|c|}
\hline \multirow[t]{3}{*}{ Thermal perception threshold $\left({ }^{\circ} \mathrm{C}\right)$} & Group & $0.63(2,32)$ & 0.53 \\
\hline & Session & $5.26(1,32)$ & 0.03 \\
\hline & Group x Session & $4.46_{(2,32)}$ & 0.02 \\
\hline \multirow[t]{3}{*}{ Cold pain threshold $\left({ }^{\circ} \mathrm{C}\right)$} & Group & $0.42(2,32)$ & 0.65 \\
\hline & Session & $9.69_{(1,32)}$ & 0.004 \\
\hline & Group x Session & $0.30_{(2,32)}$ & 0.74 \\
\hline \multirow[t]{3}{*}{ Heat pain threshold $\left({ }^{\circ} \mathrm{C}\right)$} & Group & $1.59_{(2,32)}$ & 0.22 \\
\hline & Session & $1.07_{(1,32)}$ & 0.30 \\
\hline & Group x Session & $0.05_{(2,32)}$ & 0.94 \\
\hline \multirow[t]{3}{*}{ Heat pain tolerance $\left({ }^{\circ} \mathrm{C}\right)$} & Group & $6.31_{(2,32)}$ & 0.005 \\
\hline & Session & $0.10_{(1,32)}$ & 0.75 \\
\hline & Group x Session & $0.34_{(2,32)}$ & 0.71 \\
\hline \multirow[t]{3}{*}{ Heat pain tolerance, VAS (mm) } & Group & $10.7_{(2,32)}$ & 0.000 \\
\hline & Session & $0.09_{(1,32)}$ & 0.77 \\
\hline & Group x Session & $0.12_{(2,32)}$ & 0.88 \\
\hline \multirow[t]{3}{*}{ Pressure pain, trapezius $(\mathrm{kPa})$} & Group & $0.30_{(2,32)}$ & 0.74 \\
\hline & Session & $0.24_{(1,32)}$ & 0.63 \\
\hline & Group x Session & $0.79_{(2,32)}$ & 0.46 \\
\hline \multirow[t]{3}{*}{ Pressure pain, epicondyle $(\mathrm{kPa})$} & Group & $0.01(2,32)$ & 0.98 \\
\hline & Session & $0.81_{(1,32)}$ & 0.37 \\
\hline & Group x Session & $0.19_{(2,32)}$ & 0.82 \\
\hline \multirow[t]{3}{*}{ Pressure pain, gluteal $(\mathrm{kPa})$} & Group & $0.31_{(2,32)}$ & 0.73 \\
\hline & Session & $0.73_{(1,32)}$ & 0.39 \\
\hline & Group x Session & $0.72_{(2,32)}$ & 0.49 \\
\hline Pressure pain, knee pad (kPa) & Group & $1.59_{(2,32)}$ & 0.21 \\
\hline
\end{tabular}




\begin{tabular}{llcc} 
& Session & $0.05_{(1,32)}$ & 0.83 \\
CPT, activation time (sec) & Group x Session & $0.59_{(2,32)}$ & 0.56 \\
& Group & $3.69_{(2,32)}$ & 0.03 \\
& Session & $2.91_{(1,32)}$ & 0.09 \\
& Group x Session & $2.21_{(2,32)}$ & 0.12 \\
& Group & $8.1_{(2,32)}$ & 0.001 \\
& Session & $2.06_{(1,32)}$ & 0.16 \\
CPT, maximal VAS (mm) & Group x Session & $0.64_{(2,32)}$ & 0.53 \\
& Group & $1.34_{(2,32)}$ & 0.27 \\
& Session & $0.32_{(1,32)}$ & 0.57 \\
& Group x Session & $0.81_{(2,32)}$ & 0.45 \\
& Group & $6.25_{(2,32)}$ & 0.005 \\
& Session & $2.1_{(1,32)}$ & 0.157 \\
& Group x Session & $0.60_{(2,32)}$ & 0.55 \\
\hline
\end{tabular}

CPT, cold pressor test 
Table 2. Comparison of measured outcomes between the hormonal down-regulation phase and the hormonal up-regulation phase in 16 women undergoing IVF

\begin{tabular}{lccc}
\hline Variable & Down-regulation & Up-regulation & $P$-value \\
& & & \\
\hline & & & \\
Thermal perception threshold $\left({ }^{\circ} \mathrm{C}\right)$ & $1.7(0.4)$ & $2.2(0.8)$ & 0.003 \\
Cold pain threshold $\left({ }^{\circ} \mathrm{C}\right)$ & $11.5(6.5)$ & $14.5(6.5)$ & 0.04 \\
Heat pain threshold $\left({ }^{\circ} \mathrm{C}\right)$ & $43(3.3)$ & $43.5(3.4)$ & 0.37 \\
Heat pain tolerance $\left({ }^{\circ} \mathrm{C}\right)$ & $49.5(2.2)$ & $49.5(2.2)$ & 0.52 \\
Heat pain tolerance, $\mathrm{VAS}(\mathrm{mm})$ & $78(12)$ & $80(14)$ & 0.44 \\
Pressure pain, trapezius $(\mathrm{kPa})$ & $339(120)$ & $331(110)$ & 0.52 \\
Pressure pain, epicondyle $(\mathrm{kPa})$ & $268(86)$ & $255(97)$ & 0.20 \\
Pressure pain, gluteal $(\mathrm{kPa})$ & $426(174)$ & $455(240)$ & 0.46 \\
Pressure pain, knee pad $(\mathrm{kPa})$ & $339(123)$ & $340(140)$ & 0.93 \\
CPT, activation time $(\mathrm{sec})$ & $9.4(6.4)$ & $10(8.4)$ & 0.58 \\
CPT, tolerance time $(\mathrm{sec})$ & $60(66)$ & $62(66)$ & 0.77 \\
CPT, maximal VAS score $(\mathrm{mm})$ & $85(17)$ & $89(6)$ & 0.30 \\
CPT, post-stimulation VAS $(\mathrm{mm})$ & $69(30)$ & $78(20)$ & 0.15 \\
S-estradiol, $(\mathrm{pmol})$ & $65(26)$ & $5188(2523)$ & 0.000 \\
\hline
\end{tabular}

Response data are given as mean (SD). CPT, cold pressor test. 
Table 3. Session-to-session effects on responses to temperature and pain stimuli in two control groups

\begin{tabular}{|c|c|c|c|c|c|c|}
\hline \multirow[b]{2}{*}{ Variable } & \multicolumn{3}{|c|}{$\operatorname{Men}(n=10)$} & \multicolumn{3}{|c|}{ Women $(n=9)$} \\
\hline & Session I & Session II & $P$-value & Session I & Session II & $P$-value \\
\hline Thermal perception threshold $\left({ }^{\circ} \mathrm{C}\right)$ & $1.8(0.3)$ & $1.7(0.4)$ & 0.39 & $1.9(0.5)$ & $2(0.5)$ & 0.23 \\
\hline Cold pain threshold $\left({ }^{\circ} \mathrm{C}\right)$ & $14.5(7.7)$ & $16(7.9)$ & 0.15 & $13(4.9)$ & $15(4.8)$ & 0.06 \\
\hline Heat pain threshold $\left({ }^{\circ} \mathrm{C}\right)$ & $45(2.6)$ & $45(3)$ & 0.44 & $45(2.8)$ & $45.5(2.3)$ & 0.76 \\
\hline Heat pain tolerance $\left({ }^{\circ} \mathrm{C}\right)$ & $52(0.3)$ & $52(0.3)$ & 0.44 & $50(1.5)$ & $50.5(1.3)$ & 0.64 \\
\hline Heat pain tolerance, VAS (mm) & $51(11)$ & $50(15)$ & 0.84 & $67(27)$ & $67(21)$ & 0.92 \\
\hline Pressure pain, trapezius (kPa) & $301(79)$ & $322(79)$ & 0.27 & $308(91)$ & $310(67)$ & 0.92 \\
\hline Pressure pain, epicondyle (kPa) & $270(105)$ & $262(85)$ & 0.7 & $261(64)$ & $259(56)$ & 0.92 \\
\hline Pressure pain, gluteal $(\mathrm{kPa})$ & $456(98)$ & $496(117)$ & 0.07 & $431(117)$ & $413(112)$ & 0.34 \\
\hline Pressure pain, knee pad (kPa) & $427(150)$ & $437(143)$ & 0.63 & $385(120)$ & $367(97)$ & 0.45 \\
\hline CPT, activation time (sec) & $19(10)$ & $19(10)$ & 0.97 & $16(10)$ & $29(33)$ & 0.18 \\
\hline $\mathrm{CPT}$, tolerance time (sec) & $194(119)$ & $217(122)$ & 0.29 & $97(91)$ & $106(104)$ & 0.56 \\
\hline
\end{tabular}




\begin{tabular}{|c|c|c|c|c|c|c|}
\hline CPT, maximal VAS score $(\mathrm{mm})$ & $76(16)$ & $81(15)$ & 0.3 & $84(14)$ & $80(16)$ & 0.59 \\
\hline CPT, post-stimulation VAS (mm) & $52(23)$ & $54(24)$ & 0.74 & $84(12)$ & $87(7.6)$ & 0.39 \\
\hline
\end{tabular}

Response data are given as mean (SD). CPT, cold pressor test. 
Table 4. Correlation between serum estradiol level and measured outcomes during the upregulation phase in women undergoing IVF.

\begin{tabular}{lcc}
\hline \multicolumn{1}{c}{ Outcome } & $r$ & P-value \\
\hline Thermal perception threshold $\left({ }^{\circ} \mathrm{C}\right)$ & 0.35 & 0.18 \\
Cold pain threshold $\left({ }^{\circ} \mathrm{C}\right)$ & -0.55 & 0.02 \\
Heat pain threshold $\left({ }^{\circ} \mathrm{C}\right)$ & 0.46 & 0.07 \\
Heat pain tolerance $\left({ }^{\circ} \mathrm{C}\right)$ & 0.2 & 0.45 \\
Heat pain tolerance, $\mathrm{VAS}(\mathrm{mm})$ & 0.11 & 0.66 \\
Pressure pain, trapezius $(\mathrm{kPa})$ & 0.15 & 0.56 \\
Pressure pain, epicondyle $(\mathrm{kPa})$ & 0.13 & 0.62 \\
Pressure pain, gluteal $(\mathrm{kPa})$ & 0.12 & 0.63 \\
Pressure pain, knee pad $(\mathrm{kPa})$ & 0.25 & 0.33 \\
CPT, activation time $(\mathrm{sec})$ & 0.36 & 0.17 \\
$\mathrm{CPT}$, tolerance time $(\mathrm{sec})$ & 0.3 & 0.24 \\
$\mathrm{CPT}$, maximal VAS score $(\mathrm{mm})$ & 0.08 & 0.75 \\
CPT, post-stimulation, VAS $(\mathrm{mm})$ & -0.12 & 0.64 \\
\hline
\end{tabular}

